\title{
SUCESSÃO FAMILIAR X SUCESSÃO PROFISSIONAL: o caso de uma organização do setor agroindustrial
}

\section{FAMILY SUCCESSION X PROFESSIONAL SUCCESSION: Case of an organization of the agroindustrial sector}

\author{
Profa. Dra. Lesley Carina do Lago Attadia Galli - lesley.attadia@unesp.br \\ UNESP - FCAV- Jaboticabal - SP - Brasil \\ Profa. Dra. Cristiane Sonia Arroyo - csarroyo@terra.com.br \\ IFSULDEMINAS - Poços de Caldas - MG - Brasil \\ Prof. Me. Rafael Altafin Galli - rafaelaltafin@gmail.com \\ UEMG - Passos - MG - Brasil \\ Profa. Dra. Glaucia Aparecida Prates - g.prates@ unesp.br \\ UNESP - Itapeva - SP - Brasil \\ Livia Rodrigues Anhesini - livia0906@ hotmail.com \\ Graduada em Administração \\ UNESP - FCAV- Jaboticabal - SP - Brasil
}

\section{RESUMO}

No papel de gestor de empresas familiares encontra-se o fundador, que com o tempo deixará esse cargo para seus herdeiros ou então para um profissional especializado na área. Esse momento na empresa se chama de sucessão e nele vemos muitos casos de falência de empresas pela condução inadequada do processo. $\mathrm{O}$ presente trabalho tem por objetivo compreender como funciona essa transição de gerenciamento em uma usina na região de Araçatuba-SP, que por cerca de vinte anos teve sua gestão familiar, e nos últimos dois anos passou sua administração para gestores externos. Por meio de entrevistas qualitativas dirigidas aos gerentes dos setores, diretor e o gestor da família que decidiu profissionalizar sua empresa, procura avistar vantagens e desvantagens desse processo, bem como suas novas perspectivas para a empresa.

Palavras-chave: Empresa familiar, Profissionalização, Setor sucroenergético.

\begin{abstract}
As the manager of these companies we find the founder, who will eventually leave this position, either to his heirs or to a professional specialized in the field. This moment in the company is called succession and in it, we see many cases of bankruptcy of companies by bad conduct of the process. This paper aims to understand how this transition of management works in a plant in the region of Araçatuba-SP, which for twenty years has had family
\end{abstract}




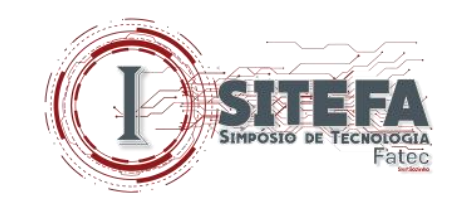

management, and in the last two years has passed its management to external managers. Through qualitative interviews directed to the managers of the sectors, director and the manager of the family who decided to professionalize their company, they looked for advantages and disadvantages of this process, as well as their new perspectives for the company.

Keywords: Family business, Professionalization, Sugarcane industry.

\section{DOI:}

\section{INTRODUÇÃO}

Empresas familiares compõem a maioria dos negócios a nível mundial, como aqui no Brasil. Nos Estados Unidos, cerca de 50\% das empresas se iniciaram em família e se organizam como grupos familiares. No Brasil, estima-se que dos 300 maiores grupos empresariais, 90\% são formados por empresas familiares (ALTAF; TROCOLLI, 2010).

O setor sucroalcooleiro é um dos mais representativos em termos econômicos no Brasil, durante muito tempo, foi formado por empresas tipicamente familiares, que recebiam do governo incentivos financeiros substanciais para manter o crescimento no mercado (SHIKIDA; BACHA, 1999).

Uma empresa familiar pode ser definida como uma organização em que os membros de uma mesma família detêm a propriedade, o controle e a gestão de uma organização (DONELLEY, 1967; LODI, 1986; LEONE, 1991; ADACHI, 2006; GALLI, 2015). A empresa familiar é bastante peculiar, pois, na maior parte das vezes, são os laços familiares que determinam a ocupação de posições estratégicas na administração e a sucessão do poder (ULRICH, 1997; BORNHOLDT, 2005; CUCCULELLI; BETTINELLI, 2015).

A sucessão de poder em uma empresa familiar é crítica para a sobrevivência deste tipo de organização porque é um importante processo de mudança (SCHEFFER, 1995; OLIVEIRA, 1999; ESTOL; FERREIRA, 2006; CANÇADO, 2013). Leone (1991) define sucessão como o rito de transferência de poder e capital em uma organização familiar. Por meio desse rito, o fundador decide se passa o poder para um membro da família ou se opta por profissionalizar a empresa, colocando no comando da organização alguém que não pertence à 


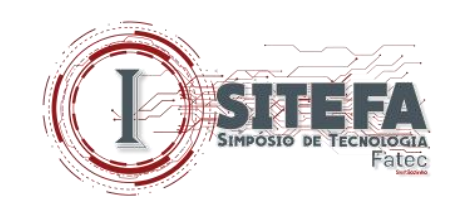

família (WERNER; SOUZA, 2012). Tanto a sucessão familiar quanto a sucessão profissional apresentam aspectos facilitadores e restritivos (NASCIMENTO; ZORZANELLI, 2012).

Os problemas relacionados à sucessão levam de três a cinco anos para serem solucionados, constituindo-se em um dos fatores de maior impacto na mortalidade das empresas familiares (MOREIRA, 2010; ULRICH, 1997; LEONE, 2005; GALLI, 2015). Dentro do contexto apresentado, este trabalho apresenta a seguinte questão de pesquisa: quais os fatores facilitadores e restritivos no processo de sucessão das empresas familiares do setor sucroalcooleiro?

O objetivo geral desta pesquisa é mapear o processo de sucessão de uma empresa familiar do setor sucroalcooleiro localizada no município de Araçatuba, identificando os fatores facilitadores e restritivos. Com intento de alcançar o objetivo geral proposto, os objetivos específicos são: mapear os fatores críticos de sucesso no processo de sucessão familiar e sucessão profissional, e estabelecer as diferenças entre eles; e analisar o processo de sucessão de uma empresa familiar do setor sucroalcooleiro, além de identificar os fatores facilitadores e restritivos da sucessão.

Quanto à importância, o tema sucessão é um dos assuntos mais pesquisados sobre o tema empresas familiares (CANÇADO et al., 2013). Além disso, o processo sucessório é tido como uma "caixa preta" para muitos gestores de empresas familiares, já que o resultado desse processo (sucesso ou fracasso) pode levar tanto ao o crescimento, ou então, comprometer a continuidade do negócio (TEIXEIRA; CARVALHAL, 2013).

\section{EMPRESA FAMILIAR E SUCESSÃO}

O conceito de empresa familiar é amplo, não tendo uma única definição, tampouco um só autor que as caracteriza, pois engloba os aspectos sociais, culturais e organizacionais. Para Bethlen (2002) cerca de $90 \%$ dos grandes grupos empresariais brasileiros são de empresas familiares. No Brasil, para Leone (2005 apud CANÇADO et al., 2011) "as empresas familiares são responsáveis por quase $48 \%$ do PIB e por $60 \%$ dos empregos".

Cançado et al. (2013) definem que empresa familiar é aquela na qual duas ou mais pessoas de uma mesma família (ou de várias famílias, em empresas multifamiliares) são proprietários/acionistas e/ou participam da gestão do negócio. Dentro de organizações 


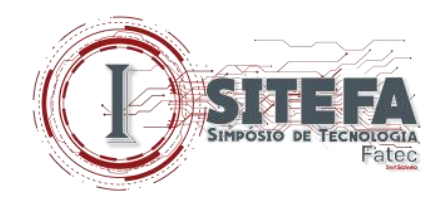

familiares, a cultura e todo seu escopo estão associados diretamente à figura de seu fundador (FARIA, VIZEU, 2014). Galli (2015, p. 2) aponta a junção de autores que falam sobre o tema e que mostram alguns pontos de caracterização da empresa familiar:

i- $\quad$ É uma organização que está diretamente ligada a uma ou mais famílias, sendo de capital aberto ou fechado.

ii- $\quad$ É uma organização cujas tomadas de decisões e gestão como um todo é feita por um ou mais membros da família, ou alguém escalado para tal função por ela.

iii- É uma organização onde os cargos principais e de confiança são designados para parentes.

iv- $\quad$ A família deixa clara sua visão nas crenças e valores transmitidos.

v- Há uma influência direta das atitudes dos membros da família.

vi- $\quad$ A sucessão é fortemente ligada aos laços familiares.

O Quadro 1 mostra um histórico da evolução conceitual de empresas familiares.

\begin{tabular}{|l|l|l|}
\hline \multicolumn{1}{|c|}{ QUTOdro 1 - Breve evolução conceitual de empresas familiares } \\
\hline Donelley & 1967 & $\begin{array}{l}\text { QuAC DESIÇA DA EMPRESA FAMILIAR } \\
\text { organizacional é fortemente influenciada pelo fundador. }\end{array}$ \\
\hline Lodi & 1986 & $\begin{array}{l}\text { A empresa deve ter em sua cultura organizacional a imagem de seu } \\
\text { fundador. }\end{array}$ \\
\hline Leone & 1991 & $\begin{array}{l}\text { A sucessão tem que ser entre membros da família, valores do fundador } \\
\text { sempre claros. }\end{array}$ \\
\hline Lodi & 1998 & $\begin{array}{l}\text { A empresa deve ter em sua cultura organizacional a imagem de seu } \\
\text { fundador. }\end{array}$ \\
\hline Cançado & 2013 & A empresa deve ter dois ou mais familiares como gestores. \\
\hline
\end{tabular}

Fonte: elaborado pelos autores

\subsection{Sucessão em Empresa Familiar}

Alcântara e Machado Filho (2014) dizem que "a sucessão, em empresas familiares, representa a continuidade de um negócio entre as gerações de uma mesma família”. Galli 2015 destaca que a sucessão representa o poder da continuidade não só do nome de uma de família como também de sua história. Mesmo quando planejada, a decisão de sucessão pode gerar conflitos entre os familiares e insegurança entre os funcionários, podendo impactar no 


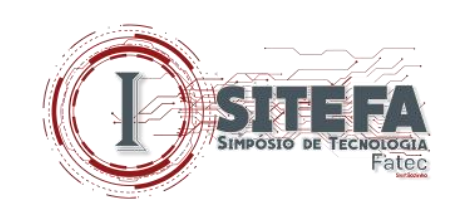

clima organizacional, dificultar a operacional da organização e comprometer a continuidade do negócio (COSTA et al., 2015); e ganha ainda maior proporção, quando ocorre por ocasião de doença ou morte repentina do dirigente, podendo levar até mesmo a liquidação da empresa (ELOI; CLARO; COSTA, 2016). O Quadro 2 apresenta conceitos de sucessão.

Quadro 2: Conceitos de sucessão

\begin{tabular}{|l|l|l|l|}
\hline \multicolumn{2}{|c|}{ SUCESSÃO FAMILIAR } & \multicolumn{3}{|l|}{ SUCESSÃO PROFISSIONAL } \\
\hline $\begin{array}{l}\text { Continuidade dos negócios por meio dos } \\
\text { familiares. }\end{array}$ & $\begin{array}{l}\text { Continuidade da empresa dada por } \\
\text { executivos. }\end{array}$ \\
\hline $\begin{array}{l}\text { Falta de planejamento durante o processo. } \\
\begin{array}{l}\text { Estratégia elaborada e decidida. } \\
\text { fundinuidade da cultura organizacional do }\end{array}\end{array}$ & $\begin{array}{l}\text { Possibilidade de alteração na cultura } \\
\text { organizacional. }\end{array}$ & & \\
\hline
\end{tabular}

Fonte: elaborado pelos autores

\section{PROCEDIMENTOS METODOLÓGICOS: características da pesquisa}

Trata-se de uma pesquisa empírica, que, de acordo com Salomon (1991) tem como finalidade a aplicação de conceitos (sucessão) no diagnóstico de uma realidade empresarial (empresa familiar). A pesquisa é de caráter descritivo, que tem como objetivo definir melhor o problema de pesquisa sobre o tema sucessão em empresas familiares, apresentando contribuições e caracterizando as variáveis intervenientes (FACHIN, 2006).

Classificada como pesquisa qualitativa na análise dos dados que tem como propósito o aprofundamento da compreensão acerca de um problema de pesquisa relacionado a um grupo social e/ou uma organização (GERHARDT; SILVEIRA, 2009). O procedimento técnico de investigação usado é o método o estudo de caso que pode ser conceituado como uma forma de se fazer pesquisa social empírica, que tem como objetivo investigar um fenômeno atual dentro de seu contexto de vida real, utilizando-se múltiplas fontes de evidência (YIN, 2001).

\subsection{Variáveis de Pesquisa}

A seguir as variáveis de pesquisa são apresentadas no Quadro 3. 


\section{(1) 1 anteg}

Quadro 3 - Variáveis da Pesquisa sobre sucessão familiar e profissional em empresa familiar

\begin{tabular}{|c|c|c|}
\hline VARIÁVEL & CRITÉRIOS & $\begin{array}{l}\text { QUESTÕES DE SUCESSÃO FAMILIAR E } \\
\text { PROFISSIONAL }\end{array}$ \\
\hline $\begin{array}{l}\text { GESTÃO DO } \\
\text { FUNDADOR }\end{array}$ & $\begin{array}{l}\text { - Caracterização } \\
\text { da gestão do } \\
\text { fundador }\end{array}$ & $\begin{array}{l}\text { - Quais principais características do fundador como } \\
\text { gestor? } \\
\text { - Quais foram as principais estratégias adotadas pelo } \\
\text { gestor que contribuíram para a sobrevivência? }\end{array}$ \\
\hline \multirow{4}{*}{$\begin{array}{l}\text { SUCESSÃO } \\
\text { FAMILIAR }\end{array}$} & $\begin{array}{l}\text { - Fatores } \\
\text { Motivadores }\end{array}$ & $\begin{array}{l}\text { - Como se deu a decisão de que era o momento de } \\
\text { realizar a sucessão? Quais motivos que levaram ao } \\
\text { fundador a esta decisão? } \\
\text { - Descreva quais eram as estratégias da empresa e } \\
\text { como era seu desempenho competitivo no momento } \\
\text { da decisão da sucessão. }\end{array}$ \\
\hline & $\begin{array}{l}\text { - Etapas } \\
\text { para a } \\
\text { implantação }\end{array}$ & $\begin{array}{l}\text { - Como o sucessor familiar foi escolhido? } \\
\text { - Como o sucessor familiar foi preparado para assumir } \\
\text { o comando da empresa? } \\
\text { - Como a escolha do sucessor familiar foi recebida } \\
\text { pelos outros membros da família? } \\
\text { - Como o sucessor familiar foi recebido pelos } \\
\text { funcionários? } \\
\text { - Como se deu o processo de transição de poder entre } \\
\text { fundador e sucessor familiar? }\end{array}$ \\
\hline & $\begin{array}{l}\text { - Fatores } \\
\text { facilitadores }\end{array}$ & $\begin{array}{l}\text { - Quais foram os fatores que interferiram no processo } \\
\text { de sucessão familiar positivamente? } \\
\text { - Quais os principais benefícios obtidos pela empresa } \\
\text { ao adotar um sucessor familiar? }\end{array}$ \\
\hline & $\begin{array}{l}\text { - Fatores } \\
\text { restritivos }\end{array}$ & $\begin{array}{l}\text { - Quais foram as principais dificuldades enfrentadas } \\
\text { pelo sucessor durante o processo de sucessão? } \\
\text { - Houve divergências /conflitos entre o fundador e o } \\
\text { sucessor durante o processo de sucessão familiar? } \\
\text { - Quais foram os fatores que interferiram no processo } \\
\text { de sucessão familiar negativamente? }\end{array}$ \\
\hline \multirow{2}{*}{ 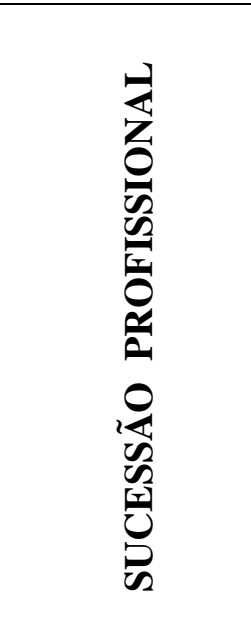 } & $\begin{array}{l}\text { - Fatores } \\
\text { Motivadores }\end{array}$ & $\begin{array}{l}\text { - Como se deu a decisão de que era o momento de } \\
\text { realizar a sucessão profissional, contratando um } \\
\text { gestor externo à família? Quais motivos levaram o } \\
\text { sucessor familiar a tomar esta decisão? } \\
\text { - Descreva quais eram as estratégias da empresa e } \\
\text { como era seu desempenho competitivo no momento } \\
\text { da decisão da sucessão profissional. }\end{array}$ \\
\hline & $\begin{array}{l}\text { - Etapas } \\
\text { para a } \\
\text { implantação }\end{array}$ & $\begin{array}{l}\text { - Como o sucessor profissional foi escolhido? } \\
\text { - Como o sucessor profissional foi preparado para } \\
\text { assumir o comando da empresa? } \\
\text { - Como a escolha do sucessor profissional foi recebida } \\
\text { pelos outros membros da família? } \\
\text { - Como o sucessor profissional foi recebido pelos }\end{array}$ \\
\hline
\end{tabular}




\section{(1) SITEFA}

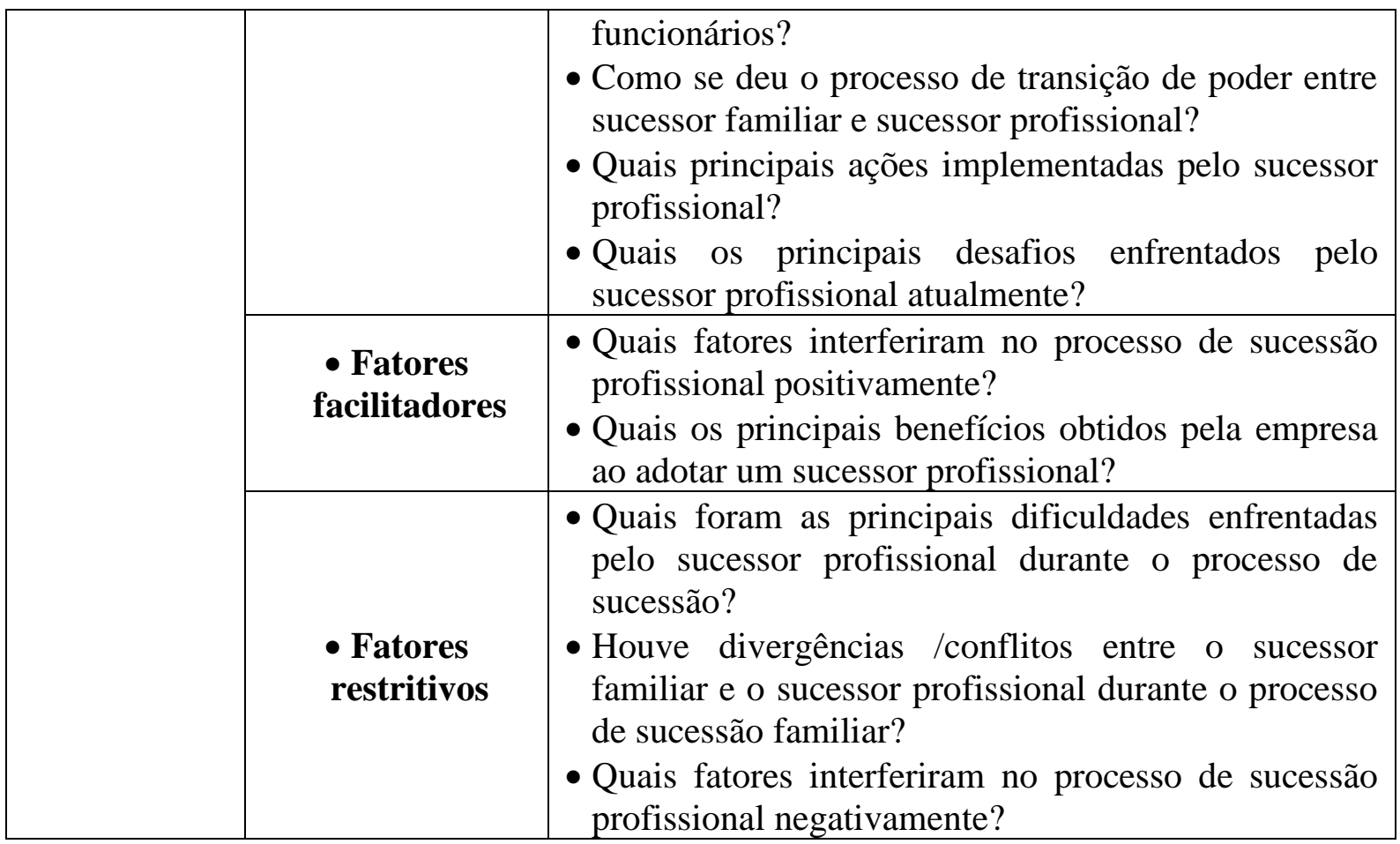

Fonte: elaborado pelos autores

\subsection{Método de coleta de dados}

Para a coleta de dados utilizou-se a entrevista em profundidade que tem como finalidade entender os significados que os entrevistados atribuem às questões e situações relativas ao tema estudado (GODOI; BANDEIRA-DE-MELLO; SILVA, 2006). Um roteiro de perguntas abertas foi feito com base nas variáveis de análise (Quadro 3), as questões que surgiram durante a entrevista foram adicionadas. As entrevistas realizadas foram gravadas com a devida autorização dos entrevistados, nos meses de abril e maio de 2017 com um tempo médio de duração de 2 horas. Depois foram transcritas para facilitar a análise de dados.

Foi definido que para atender os objetivos da pesquisa era preciso obter a visão não só do CEOs (sucessor familiar e sucessor profissional), como também dos gerentes departamentais para melhor retratar as diferenças entre os dois tipos de sucessão. A partir desse critério, foram selecionadas seis pessoas para realização das entrevistas: 


\section{(1) 1 anmos}

Quadro 4 - Entrevistados para os dois tipos de sucessão: familiar e profissional

\begin{tabular}{|l|l|}
\hline ENTREVISTADO & \multicolumn{1}{|c|}{ CARACTERÍTICAS DO ENTREVISTADO } \\
\hline $\begin{array}{l}\text { Gerente do } \\
\text { Repartamento de }\end{array}$ & $\begin{array}{l}\text { 30 anos de idade, iniciou na usina como assistente administrativo na } \\
\text { empresa há } 10 \text { anos, onde cresceu em seu departamento, sua formação } \\
\text { é em gestão de empresas. }\end{array}$ \\
\hline $\begin{array}{l}\text { Gerente do } \\
\text { departamento de } \\
\text { Contabilidade }\end{array}$ & $\begin{array}{l}\text { Trabalhou nos dois momentos na usina, na fase inicial com o sucessor } \\
\text { familiar, ano de } 2010 \text { e após como o sucessor profissional em } 2014 . \\
\text { Formado em contabilidade. }\end{array}$ \\
\hline Gerente de TI & $\begin{array}{l}\text { Está há 26 anos na empresa, iniciou como cortador de cana, teve um } \\
\text { plano de carreira até chegar à gerência. Formado em sistema da } \\
\text { informação. }\end{array}$ \\
\hline Diretor financeiro & $\begin{array}{l}\text { Trabalha há um ano e meio na empresa, contratado como diretor } \\
\text { financeiro em fevereiro de 2016, tem mais de 20 anos de experiência } \\
\text { na área. Formado em administração de empresas. }\end{array}$ \\
\hline Proprietária da & $\begin{array}{l}53 \text { anos, médica. Trabalhou como gestora da empresa, é do conselho } \\
\text { administrativo atualmente. Herdeira e sucessora familiar. }\end{array}$ \\
\hline usina & \begin{tabular}{l}
55 anos, formação em engenharia civil e é esposo da proprietária. \\
\hline
\end{tabular}
\end{tabular}

Fonte: elaborado pelos autores

A técnica de análise de dados foi a análise de discurso que permite ao pesquisador realizar uma análise contextual, na qual os argumentos tomam sentido em relação aos atores que o enunciam (GODOI; BANDEIRA-DE-MELLO; SILVA, 2006).

Esta etapa da pesquisa foi facilitada pela definição das variáveis de pesquisa do Quadro 3. A empresa escolhida como unidade de análise pertence ao setor sucroalcooleiro e está localizada na região de Araçatuba - SP. A organização tem representatividade econômica na região, selecionada por conveniência (MALHOTRA et al., 2005), e atendeu à três critérios desta pesquisa: a) é uma organização familiar do setor sucroalcooleiro; b) passou pelos processos de sucessão familiar e profissional; e c) aceitou participar da pesquisa. 


\section{RESULTADOS E DISCUSSÃO DO ESTUDO DE CASO}

A Empresa sucroalcooleira se localiza no interior do Estado de São Paulo, comercializa açúcar e álcool, a produção de açúcar é direcionada para Rússia, Canadá, Egito, Argélia, Índia e Síria. Fundada em 1981, se trata de uma empresa familiar, administrada por seu fundador. Tem cerca de 1.000 colaboradores e conta com cursos profissionalizantes de especialização para seus funcionários. Em sua gestão, tem o Conselho, o CEO, três diretores (financeiro, agrícola, industrial) e seis gerentes (TI, RH, suprimentos, contabilidade, agrícola, industrial). Sua colheita é cerca de $90 \%$ mecanizada, e a rotação de cultura é feita com soja e amendoim. Desde 2016 a empresa dobrou sua capacidade de geração de vapor, moagem e produção de açúcar. Segundo o site da empresa sua missão é:

A partir da cana de açúcar produzir energia e alimento dentro das melhores práticas de sustentabilidade, agregando e gerando valores socioambientais e econômicos aos acionistas, colaboradores, parceiros e comunidade.

Sua visão é:

Tornar-se uma referência no Setor SucroAlcooleiro Energético da nossa região através de um crescimento sólido dentro das melhores práticas de governança corporativa, inovando sempre e quebrando paradigmas, estabelecendo compromissos de longo prazo, construindo relacionamentos estratégicos pautados na confiança, considerando sempre em primeiro lugar o SSMA (Segurança, Saúde e Meio Ambiente) e respeito às Leis.

E por fim, seus valores são: "Ética, Transparência, Comprometimento, Confiança, Competência, Meritocracia e respeito à SSMA".

\subsection{Caracterização da gestão do fundador}

A gestão do fundador da empresa sempre foi associada ao sucesso, para os entrevistados. Ele personificava a empresa e foi um grande gestor "ele fundou uma usina e manteve, hoje em dia isso é difícil, e não fomos vendidos para nenhuma outra empresa maior" GESTOR 1. Para os funcionários que viram diferentes usinas na região serem vendidas ou mesmo falirem, estar em uma empresa que permaneceu estável por todo esse tempo representava participar de uma administração efetiva. 


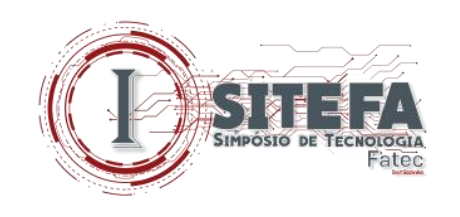

A gestão era considerada amadora, o fundador não tinha um método de trabalho estabelecido, sua equipe era constituída por familiares e amigos, e os processos não eram formalizados. De acordo com os funcionários e mesmo com sua filha, funcionava, mas não era exatamente embasada em uma estratégia, se não na visão intuitiva para negócios do próprio fundador: "A estratégia da empresa era produzir com o que tinha com o menor custo sem muito foco em políticas internas e procedimentos" HERDEIRA.

Não há apontamentos de aspectos negativos, na visão dos funcionários o fundador acertou tanto na gestão como na continuidade dos negócios. Dos quatro entrevistados, apenas dois responderam sobre a época em que o fundador atuava na empresa. Dificultando sua definição como um todo, ainda assim podendo extrair algumas considerações. Sua caracterização se encaixa na definição de Lodi (1998) de empresa familiar "empresas familiares devem ter sua imagem atrelada aos ideais de seu fundador [...] sua reputação, se relaciona diretamente com o fundador".

A participação dos funcionários era restrita, pois a gestão era centralizadora, havia limitações. Os funcionários não tinham contato direto com o fundador, mas ao mesmo tempo eles não vêm como crítica. Já a família tinha uma participação significativa, sendo designada a cargos importantes na empresa. A gestão do fundador trazia uma característica pessoal, a empresa era feita à imagem do fundador, que transparecia a confiabilidade aos funcionários, de acordo com uma caracterização feita pelo GESTOR 4 "seriedade, interesse e exemplo".

Naquela época e hoje, a empresa é admirada pelos funcionários e motivo de orgulho para a gestão atual. Nota-se sua importância quando no site da usina essa informação foi citada na apresentação da empresa. O funcionário sempre se sentiu valorizado, e tem oportunidade de crescer na empresa, o que traz uma motivação extra ao trabalhar. O dono conseguiu trazer essa característica ainda sendo uma gestão centralizadora, sempre seus funcionários alegam que ele era próximo e um patrão acessível. Um de seus méritos como gestor.

Sua família era tradicionalmente dona de usinas na região, sendo seu irmão o dono de outras unidades, portanto entre irmãos havia essa tendência à área. Entre seus dois filhos, o homem se interessava pela administração e assim que possível, foi ativo na participação da gestão, já a filha optou por medicina, e só quando foi necessário, ela assumiu a gestão. 


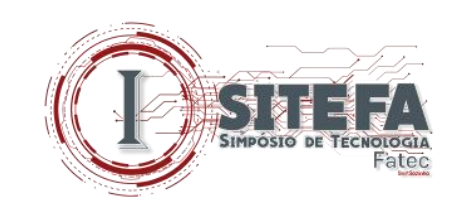

Ainda que tenha conseguido passar para os seus funcionários a característica acolhedora e de mérito, sua gestão era centralizadora, e seus funcionários escolhidos na base desse respeito à sua imagem. Era uma gestão tradicional onde ele tinha domínio de todos os processos e participava de todas as decisões, o que com o tempo passou a não atender as necessidades da empresa "Dono era diretor superintendente, havia diretores, sem áreas claramente específicas, e os gerentes não eram bem direcionados” CEO.

\subsection{Caracterização da sucessão familiar}

A sucessão familiar se deu com o falecimento do fundador, que ocorreu de maneira repentina, não sendo planejado o processo de sucessão. Não ficou evidente para os funcionários o que ocorreu na época, e como se deu o processo, o que o caracteriza como informal. Nesse momento, o filho que já tinha contato com a empresa e interesse em assumir o controle da gestão, acabou ficando, como decisão repentina, responsável pela empresa.

A família na gestão do fundador aproveitava de benefícios na empresa, apesar de não serem profissionais na área, ocupavam cargos gerenciais, o que enfatizava a estrutura hierárquica a qual mantinham. No processo de sucessão, por passar a empresa para a herdeira, no início, não houveram mudanças, porém, ela por questões antes ignoradas (projetos sociais, cuidado com meio ambiente, cultura centralizadora), para o Gestor 2, passou a ser mais participativa.

Após assumir, a sucessora tentou lidar com defeitos como o distanciamento na relação patrão-funcionário, descentralizando funções, o que foi percebido por alguns gestores, e nem tanto por outros. Sob seu ponto de vista, foi bem aceita tanto pelos funcionários, como pela família, ainda que tenha lidado com um pouco de resistência à mudança por parte de alguns colaboradores.

Para os funcionários, agora a formalização e padronização de projetos estava mais fácil, e a substituição da gerência antiga e "familiar" por especialistas nas áreas trouxe uma maior organização e aproximação da mesma. Na gestão do fundador, os funcionários sabiam que podiam crescer, mas até certo ponto, pois gerência e diretoria eram escolhidas pelo mesmo e, através de seus critérios, aos poucos com a sucessora, tentaram-se mudar essa visão, inclusive dois gerentes começaram em cargos simples na empresa, e puderam crescer. Para o 


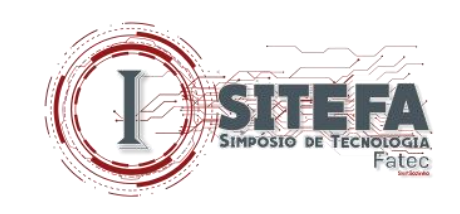

atual CEO, essa mudança veio em uma época que demandava alterações na gestão: “A necessidade de profissionalizar práticas e processos, estavam obsoletos."

\subsection{Caracterização da sucessão profissional}

Conforme a usina assumiu um caráter menos centralizador e passou a colher os benefícios de uma estratégia mais formal e menos familiar, foi questão de tempo até a gestora decidir profissionalizar a empresa. Estava havendo um "esgotamento do modelo pela falta de liderança" GESTOR 4, o que levou a decisão de profissionalizar a gestão.

Na gestão de seu pai, não havia uma estratégia definida, o que prejudicou o andamento da empresa, "entrei sabendo da necessidade de troca do corpo de funcionários, principalmente os responsáveis por cada área, até os funcionários que ficaram entenderem essas mudanças, tive que lidar com insegurança e resistência" CEO. A partir disso, a profissionalização se formalizou, e como atitude inicial, profissionais qualificados foram contratados em cada área, com substituição de gerentes e supervisores antigos.

A profissionalização iniciou-se com a troca do corpo de diretores, a intenção era a mudança a partir de suas experiências para que a nova gestão desse certo. Logo, os membros da família não ocupariam mais cargos administrativos, mas participariam de um Conselho, que para o Gestor 4, poderia ser mais profissional, o próximo passo seria implementar a profissionalização e a "Criação do Conselho Profissional e Governança Corporativa Completa."

Para os funcionários a gestão está mais direcionada, os setores estão se aprimorando e oferecendo boas chances para aqueles que fazem um bom trabalho e almejam um plano de carreira. Contratações externas dão maior suporte para os setores.

A empresa está em plena fase de mudança, o corpo de diretores está fechado, aos poucos, o quadro de funcionários toma sua forma de acordo com a nova fase, buscando a otimização dos resultados. Para os entrevistados, a empresa está mais evoluída, mas tem sua característica familiar, o que vem a ser uma barreira no crescimento, mas também está sendo bem contornada pelos diretores. 


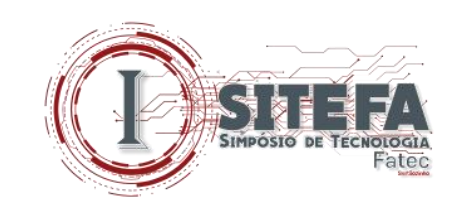

\subsection{Considerações sobre a gestão do fundador}

O dono da empresa deixou sua cultura organizacional enraizada na Usina. O fundador era centralizador e procurava atender a todas as funções, o que funcionou durante sua gestão, também por meio de funcionários que eram amigos próximos e familiares. Essas características são usuais em empresas familiares da primeira geração, nas quais o fundador demonstra dificuldade em confiar em terceiros para "cuidar" de seus negócios.

Ainda que com uma administração pouco estratégica, sua boa visão permitiu que os negócios prosperassem sempre voltados para o lucro, e conseguindo crescer na região. Sua gestão apesar de contar com falhas, de forma geral conseguiu se mostrar forte e trouxe uma base sólida para a próxima geração, que assumiu a gerência de forma repentina devido à morte do fundador.

\subsection{Considerações sobre a sucessão familiar}

A sucessão na empresa estudada ocorreu de forma repentina, com o falecimento do dono em um acidente. Dada a situação, de imediato o filho assumiu o seu papel, até a divisão da herança se concluir. Após esse período, a filha do dono assumiu a gestão da empresa. Para Adachi (2006), a sucessão deveria ser planejada e não associada ao falecimento do fundador. O filho sempre foi preparado para o cargo, já trabalhava na empresa e sabia que iria assumir a gestão em algum momento. E assim ocorreu, porém logo depois sua irmã assumiu a gestão da mesma. A falta de planejamento durante o processo fica evidente quando logo depois de assumir a gestão a herdeira decide profissionalizar a empresa. A premissa de que o planejamento é fundamental durante esse processo.

\subsection{Considerações sobre a sucessão profissional}

Como dito anteriormente, em determinado momento de sua gestão, a herdeira compreendeu que tinha dificuldades administrativas, as quais seria melhor contar com ajuda externa para auxiliá-la. Nesse momento decidiu profissionalizar a gestão da empresa. A falta de aptidão para o cargo exercido fez com que a herdeira cedesse à pressão. 


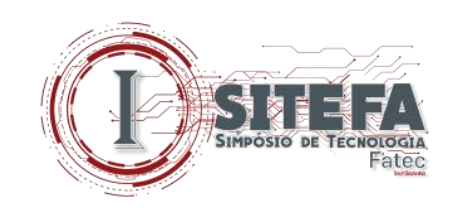

Não houve processo seletivo na decisão do profissional, o CEO contratado se tratava do esposo da herdeira, que trabalhava na gestão de outra empresa e tinha experiência na área, o que facilitou o processo, ainda que a esposa alegasse que primeiramente ele era um funcionário capaz, depois seu marido. Adachi (2006) "profissionalizar não significa que proprietários sejam excluídos de cargos relevantes da empresa. Um familiar pode ocupar até o mais elevado posto hierárquico da empresa, desde que comprove ser o profissional mais adequado para o cargo."

Verifica-se uma conversão entre a sucessão familiar e a sucessão profissional na gestão, houve uma racionalização de procedimentos, que trouxe maturidade necessária para a empresa, pois usava práticas amadoras. Ao deixar a herdeira a par da gestão e auxiliando na imagem da empresa, a personificação da empresa à imagem do dono ainda é presente.

\section{CONSIDERAÇÕES FINAIS}

O processo de sucessão se deu de imediato com o falecimento do fundador. Dessa forma, etapas importantes foram desconsideradas, como o planejamento, treinamento do sucessor, a informação na empresa. Com a ausência do fundador, um dos filhos assumiu e com a divisão da herança, sua filha que é médica ficou responsável pela unidade. O fato de uma profissional da área da saúde assumir uma função que não estava habilitada reforça o entendimento da importância da capacitação profissional, que poderia ter acontecido anteriormente pelo seu fundador, preparando os filhos para a sucessão na empresa.

A cultura da empresa estava habituada ao jeito monopolizador de seu primeiro dono e agora sentia que não tinha mais uma direção. Ao mesmo tempo em que se notava a necessidade de descentralizar os processos e torná-los mais estratégicos. Ainda que optasse por estratégias que melhorariam a administração, na fase da sucessão familiar, a herdeira teve problemas na concretização de suas visões para a empresa chegando à conclusão que profissionalizar a gestão era a melhor alternativa. Nesse caso o processo também fugiu ao que normalmente se espera.

A profissionalização ocorreu na usina, porém o profissional especialista na área se tratava do esposo da herdeira, outra vez fazendo com que a usina pulasse etapas no processo de sucessão. Entende-se que a capacitação profissional é de suma importância para o 


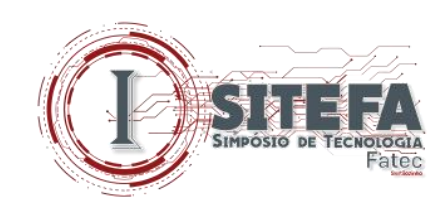

funcionamento da empresa e agora a herdeira tinha na sua empresa familiar, uma pessoa capacitada e da sua família para assumir o cargo.

Nesse caso, há um exemplo complexo no qual ainda que se trate de uma profissionalização da empresa, o profissional é um familiar, o que pode levantar o questionamento sobre como familiares podem estar preparados para assumir a direção da empresa. Agora, a partir de uma orientação especializada, as mudanças que anteriormente não foram implantadas, seriam estabelecidas. Por ser uma empresa familiar e do interior, as suas características paternalistas eram muito fortes. Os gerentes e diretores eram amigos do fundador, ou familiares, muitas vezes sem aptidão para o cargo que exerciam, o fundador centralizava suas tarefas. Era um método antigo, porém que até certo ponto funcionou na empresa.

Não existe fórmula pronta para uma boa sucessão, mas existe o entendimento dos critérios necessários para facilitarem seu crescimento. A usina, por caminhos difíceis e não programados tem conseguido se manter no mercado, crescendo mesmo em meio a tantas adversidades. O processo ainda está em andamento, mas os funcionários envolvidos colhem frutos da mudança.

Quanto às Limitações do Trabalho foi um estudo de caso realizado em uma usina, onde se entrevistou de forma qualitativa alguns gestores, bem como sua proprietária e seu atual CEO. Assim, as conclusões pertencem a esse estudo não podendo generalizar. Quanto a Trabalhos Futuros, ao longo do estudo realizado nota-se que a passagem da empresa está associada aos filhos herdeiros.

\section{REFERÊNCIAS}

ADACHI, Pedro Podboi. Família S.A: gestão de empresa familiar e soluções de conflitos. São Paulo: Atlas, 2006

ALCÂNTARA, N. B.; MACHADO FILHO, C. A. P. O processo de sucessão no controle das empresas rurais brasileiras: um estudo multicasos. Organizações Rurais \& Agroindustriais, Lavras, v.16, n.1, p. 139-151, 2014.

ALTAF, J. G.; TROCCOLI, I. R. A importância da gestão profissional em uma empresa familiar - joalheria Meridiano Ltda. Revista Economia \& Gestão, Belo Horizonte, v. 10, n. 23, p. 40-59, 2010.

BETHLEM, A. Estratégia empresarial: 4. ed. São Paulo: Atlas, 2002. 


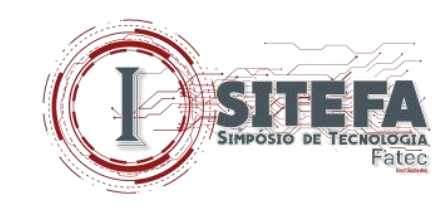

BORNHOLDT, W. Governança na empresa familiar - implementação e prática. Porto Alegre. Ed. Bookman - Artmed, 2005.

CANÇADO, V. L. et al. Ciclo de vida, sucessão e processo de governança em um empresa familiar: um estudo de caso no grupo Seculus. REAd, Porto Alegre, v. 75, n. 2, p. 485-516, 2013.

CANÇADO, A. C. et al. Gestão social: reflexões teóricas e conceituais. Cadernos EBAPE.BR, v. 9, n. 3, artigo 1, Rio de Janeiro, set. 2011, p.681-703.

COSTA, P. S. L., et al. De pai para filho: a sucessão em pequenas e médias empresas familiares. contabilidade, gestão e governança, Brasília, v.18, n.1, p.61-82, 2015.

CUCCULELLI, M.; BETTINELLI, C. Business models, intangibles and firm performance: evidence on corporate entrepreneurship from Italian manufacturing SMEs. Small Bus Econ (2015) 45: 329. Disponível em: <https://doi.org/10.1007/s11187-0159631-7>. Acesso em: 7 jan. 2019.

DONNELLEY, R. G. A Empresa Familiar. RAE-Revista de Administração de Empresas, v. 7, n. 23, abr-jun, p.161-198, 1967.

ELOI, C. B. G.; COSTA, L. V.; CLARO, J. A. C. S. A Passagem do bastão para as herdeiras: o caso de uma empresa da Região do Grande ABC Paulista em fase de preparação para a sucessão familiar. Revista de Tecnologia Aplicada, v.4, n.1, p3-23, 2016.

ESTOL, Kátia Maria Felipe; FERREIRA, Maria Cristina. O processo sucessório e a cultura organizacional em uma empresa familiar brasileira. Rev. adm. contemp., Curitiba, v. 10, n. 4, p. 93-110, Dec. 2006 . Disponível em:

$<$ http://www.scielo.br/scielo.php?script=sci_arttext\&pid=S1415-

65552006000400005\&lng=en\&nrm=iso>. Acesso em: 04 jan. 2019.

FACHIN, O. Fundamentos de Metodologia. 5a. Ed. São Paulo: Saraiva, 2006. 210 p.

GALLI, L.C.L.C; Empresas Familiares: aspectos comportamentais, estruturais, gerenciais e contextuais. Jaboticabal: FUNEP 2015

GERHARDT, SILVEIRA. Metodologia Cientifica: aspectos teóricos e conceituais. Porto Alegre. p.120, 2009.

GODOI, C. K; BANDEIRA-DE-MELLO, R. ; SILVA, A.B. (org.). Pesquisa Qualitativa em Estudos Organizacionais: paradigmas, estratégias e métodos. São Paulo: Saraiva, 2006. 460p.

LEONE, N. M. G. A sucessão não é um tabu para os dirigentes da PME. Anais. XV

ENANPAD. Belo Horizonte, p.243-257, 1991. 


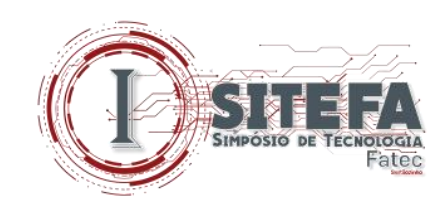

LEONE, G. P. C. N. Sucessão na Empresa Familiar. Editora Atlas, São Paulo, 2005.198 p.

LODI, J.B. A empresa familiar. São Paulo: Pioneira, 1986.172p.

A empresa familiar. 5. ed. São Paulo: Pioneira, 1998. 171p

MALHOTRA, N. K.; ROCHA, I; LAUDISIO, M. C; ALTHEMAN, E.; BORGES, F.M. Introdução à Pesquisa de Marketing. São Paulo: Pearson Prentice Hall, 2005. 428 p.

MOREIRA, M. Sebrae estima em 8,8 milhões número de micro e pequenas empresas em 2015. Agência Brasil. 2010. Disponível em: <http://memoria.ebc.com.br/agenciabrasil /noticia/2008-10-01/sebrae-estima-em-88-milhoes-numero-de-micro-e-pequenas-empresas -em-2015>. Acesso em 7 jan. 2018.

MUZZIO, H.; SILVA JÚNIOR, O. G. Eu sou melhor do que você! Gestão profissional x gestão familiar: a experiência de uma empresa de alimentação. Revista de

Empreendedorismo e Gestão de Pequenas Empresas, v. 3, n. 2, p. 3-19, 2014.

NASCIMENTO, A. P.; ZORZANELLI, G. J. Sucessão na empresa familiar: uma análise do processo sucessório de uma empresa capixaba. EGEPE, Florianópolis, 2012.

OLIVEIRA, D. P. R. Empresa Familiar: Como fortalecer o empreendimento e otimizar o processo sucessório. São Paulo: Atlas, 1999. 256 p.

SALOMON, D. V. Como fazer uma monografia. 2.ed. São Paulo: Martins Fontes, 1991. SCHEFFER, A. B. B. Fatores dificultantes e facilitadores ao processo de sucessão familiar. Revista de Administração, São Paulo v.30,n.3, p. 80-90, julho/setembro, 1995

SHIKIDA, P. F.; BACHA, C. J. Evolução da Agroindústria Canavieira Brasileira de 1975 a 1995. In: Revista Brasileira de Economia. v. 53, n. 1, Jan./Mar. 1999, p. 69-89

TEIXEIRA, CARVALHAL. Sucessão e Conflitos em Empresas Familiares: estudos de casos múltiplos em empresas na Cidade de Aracaju. Revista Alcance - Eletrônica, v.20, n.13, p.345-366, 2013.

ULRICH, S. Decifrando o mistério da empresa familiar: uma perspectiva etnológica.

Disponível em : < http://cefe.gtz.de/portugues//products/brainsto/4-97-1.htm. Data de acesso: 01/12/1997.

WERNER, F. P.; SOUZA, A. E. Sucessão na empresa familiar: estudo em um grupo empresarial. EGEPE, Florianópolis, 2012.

YIN, R. Estudo de caso: planejamento e método. 2a . Porto Alegre: Bookman, 2001 